\title{
NASA's Space Launch System Marks Critical Design Review
}

\author{
Chris Singer ${ }^{1}$
}

With completion of its Critical Design Review (CDR) in 2015, NASA is deep into the manufacturing and testing phases of its new Space Launch System (SLS) for beyond-Earth exploration. This CDR was the first in almost 40 years for a NASA human launch vehicle and marked another successful milestone on the road to the launch of a new era of deep space exploration. The review marked the 90-percent design-complete, a final look at the design and development plan of the integrated vehicle before full-scale fabrications begins and the prelude to the next milestone, design certification. Specifically, the review looked at the first of three increasingly capable configurations planned for SLS. This "Block I" design will stand 98.2 meters (m) (322 feet) tall and provide 39.1 million Newtons (8.8 million pounds) of thrust at liftoff to lift a payload of approximately 70 metric tons (154,000 pounds). This payload is more than double that of the retired space shuttle program or other current launch vehicles. It dramatically increases the mass and volume of human and robotic exploration. Additionally, it will decrease overall mission risk, increase safety, and simplify ground and mission operations - all significant considerations for crewed missions and unique, high-value national payloads. The Block 1 SLS will launch NASA's Orion MultiPurpose Crew Vehicle (MPCV) on an uncrewed flight beyond the moon and back and the first crewed flight around the moon. The current design has a direct evolutionary path to a vehicle with a 130t lift capability that offers even more flexibility to reduce planetary trip times, simplify payload design cycles, and provide new capabilities such as planetary sample returns. Every major element of SLS has hardware in production or testing, including flight hardware for the Exploration 1 (EM-1) test flight. In fact, the SLS MPCV-to-Stage-Adapter (MSA) flew successfully on the Exploration Flight Test (EFT) 1 launch of a Delta IV and Orion spacecraft in December 2014. This paper will discuss these and other technical and programmatic successes and challenges over the past year and provide a preview of work ahead before the first flight of this new capability.

\section{Introduction}

NASA has raised its human exploration sights toward deep space again for the first time since the Apollo missions to the moon. Its new goal is Mars, as well as explorations of asteroids and the moon. It has developed an increasingly independent, stepping stone philosophy that gradually increases the sphere of human exploration from Low Earth Orbit (LEO) to deep space operations in the vicinity of the moon, to fully independent missions to Mars. NASA is developing the SLS and the Orion crew vehicle as the foundational capabilities needed for missions to cislunar space and beyond. SLS is the subject of this paper. (Figure 1)

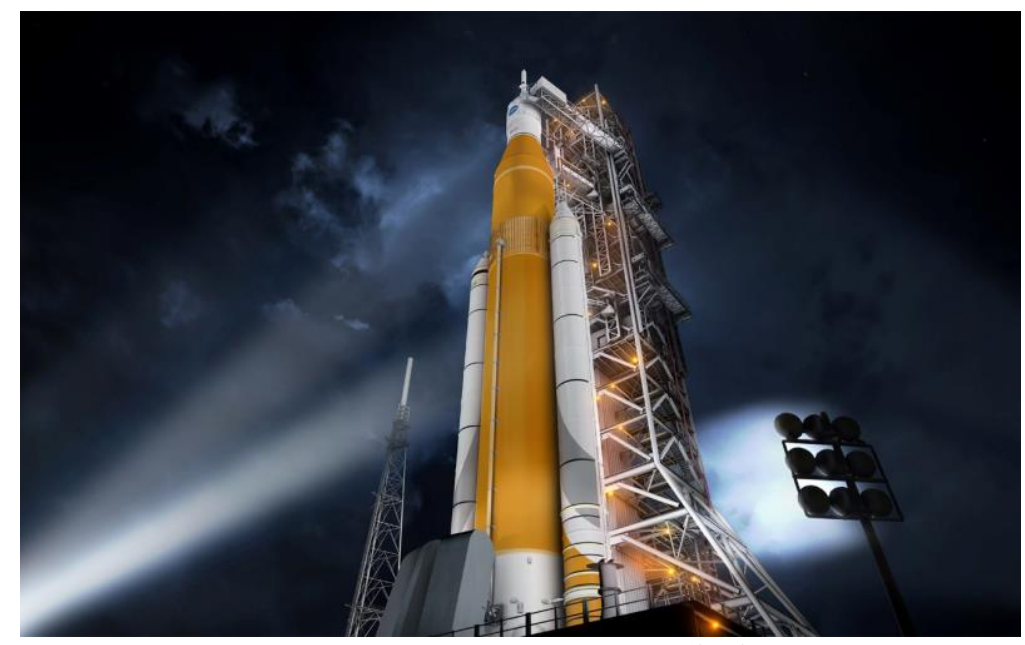

Figure 1. Artist concept of SLS.

${ }^{1}$ Deputy Chief Engineer for Engineering Integration, Office of Chief Engineer, NASA Headquarters 
SLS is an exploration class vehicle - one designed around large, unique payloads, human crews, and complex, difficult missions that demand broad attention to overall mission risk, safety, reliability, and success. SLS is designed to evolve from an initial configuration with 70 metric tons $(\mathrm{mt})(154,000$ pounds) of payload up to a configuration with $130 \mathrm{mt}$ of payload. The focus of initial work is the 70-mt Block I vehicle though much of the design is extensible to the more capable variants. (Figure 2)

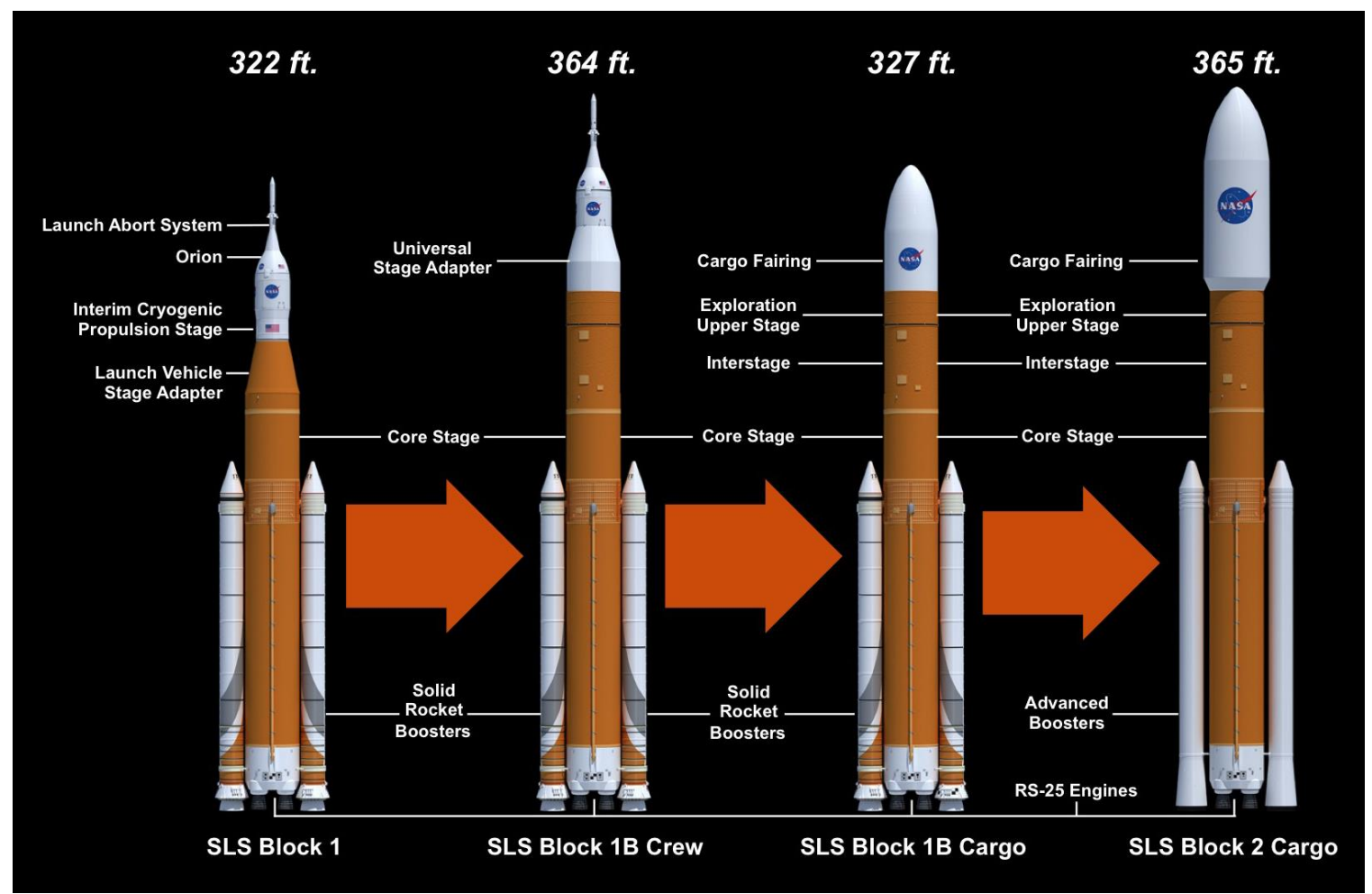

Figure 2. Artist rendering of SLS evolution from Block 1 configuration to other configurations to support different crew and cargo missions.

The backbone of the Block I is the Core Stage containing liquid hydrogen (LH2) and liquid oxygen (LOX) propellants. Main propulsion is provided by four RS-25 engines and a pair of 5-segment solid rocket boosters (SRBs) based on the space shuttle main propulsion elements tailored to the SLS mission and performance requirements. The upper stage for Block I is the Interim Cryogenic Propulsion Stage, based on the proven Delta IV Cryogenic Second Stage (DCSS) and modified with stretched propellant tanks, hydrazine bottles for attitude control, and updated avionics to accommodate SLS loads and environments.

The Block 1 design will stand 98.2 meters (m) (322 feet) tall and provide 39.1 million Newtons (8.4 million pounds) of thrust at liftoff. Its $70 \mathrm{mt}$ payload is more than double that of the retired space shuttle program or other current launch vehicles. The Block 1 SLS will launch NASA's Orion Multi-Purpose Crew Vehicle (MPCV) on an uncrewed flight beyond the moon and back in the 2018 timeframe. This mission will provide a test of the SLS vehicle and operations, subject Orion and its systems to its first deep space voyage, and release 13 suitcase-sized secondary payloads from the SLS Orion Stage Adapter section to perform investigations of the moon and other experiments.

Since the SLS Program was created in 2011, every major element of SLS has made significant progress, with contractors in place and hardware manufactured for test and/or flight. The following sections will provide major highlights of 2015 and discuss upcoming 2016 milestones on the way to the inaugural flight in 2018. 


\section{SLS PASSES CRITICAL DESIGN REVIEW}

Four years after the program was created, SLS reached Critical Design Review (CDR). For NASA, it was the first CDR on a NASA exploration class vehicle since the Saturn V in the 1960s. Some 1,088 files and 154.30 gigabyte (GB) of data were part of the comprehensive assessment process that began in May 2015 and concluded in September 2015. Thirteen review teams made up of senior engineers and aerospace experts from across NASA and industry concluded that the design is technically sound, capable and mature to continue with full scale fabrication, assembly, integration, and testing. Additionally, an independent Standing Review Board (SRB) of independent experts confirmed that the program remains on target to meet the schedule and cost goals established at Key Decision Point-C (KDP-C) and is in a good position to meet any remaining challenges during the final phase of the design program. The CDR activities culminated in a decision by the CDR Board that the Block 1 SLS vehicle is ready to proceed to production and test. SLS is now working toward Design Certification Review (DCR), which is planned for 2017.

\section{5-SEGMENT SOLID ROCKET BOOSTER}

Approximately 75 percent of SLS thrust off the launch pad will come from a pair of five-segment solid rocket boosters manufactured by Orbital ATK. These are derived from - and visually similar to - the space shuttle foursegment booster. The additional fifth motor segment provides 20 percent more thrust to help meet SLS' performance requirements. Each booster measures 177 feet long and produces 3.6 million pounds of thrust. In the SLS role, the boosters will not be reused.

Early flights will employ available remaining shuttle booster hardware. However, the booster incorporates numerous improvements beginning with manufacturing process improvements for affordability and reliability. The motor segments are lined with a new, asbestos-free insulation. A new propellant grain design reflects vehicle performance and trajectory requirements. Rounding out the major changes is a new avionics package to replace the shuttle-era avionics.

Five-segment motors have been hotfire tested four times since 2009. Most recent was Qualification Motor - 1 (QM-1) in March 2015. For QM-1, the motor was heated to 90 degrees Fahrenheit to test motor performance at the upper end of its operating range. (Figure 3, left)
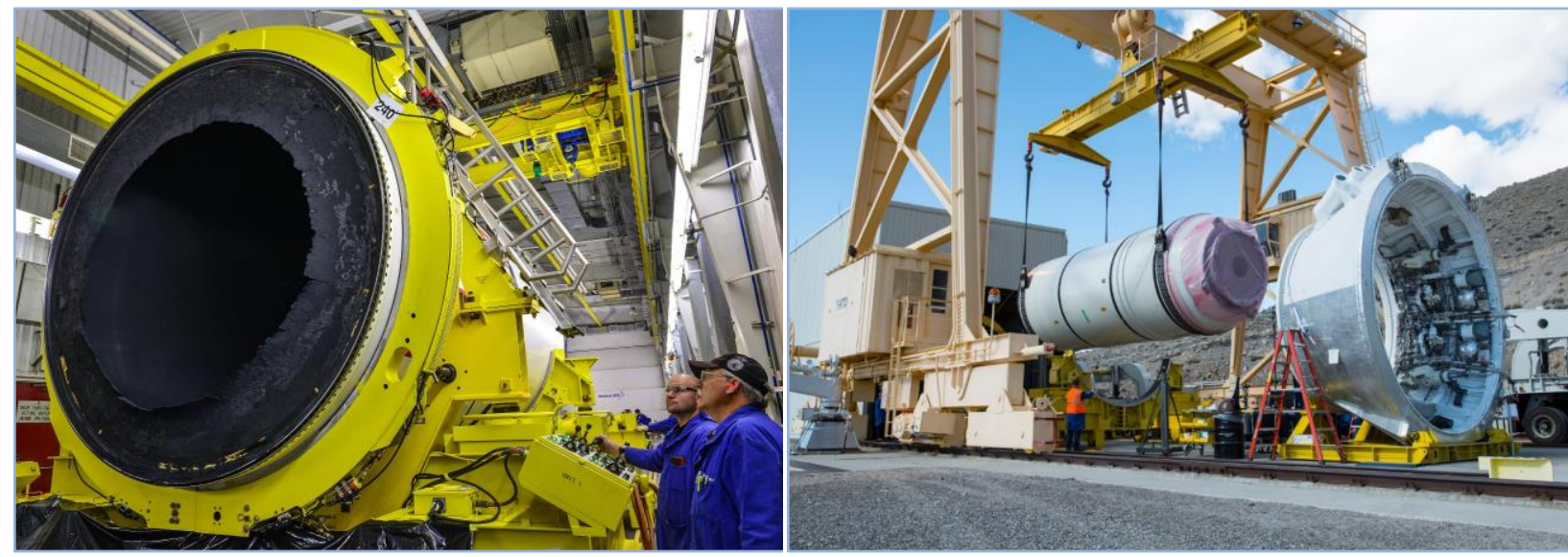

Figure 3. Left, Technicians detach QM-1 center forward segment for inspection, July 2015. Right, fifth and final motor segment for QM-2 delivered to test site, March 2016, Orbital ATK, Utah

Engineers overcame a materials issue during QM-1 preparations. During x-ray inspection of the qualification motor segments, they found several voids and un-bonds in the aft motor segment insulation and propellant. The subsequent investigation involved thousands of tests of material properties and subscale test articles. The source of the issue was found to be the new asbestos-free insulation, selected to meet new environmental laws. Although it was lighter and had better thermal properties, it also emitted gas bubbles after the insulation was applied to the motor cases. The bubbles led to the un-bonds between the propellant and insulation and voids in the propellant itself. The solution developed was the addition of a layer adhesive already used to bond the insulation to the metal case 
and an additional thin sheet of rubber insulation. Subsequent testing of segments manufactured with the changes found them to be virtually defect-free and well within safety requirements. The QM-1 test was successfully conducted in March 2015. Disassembly and inspection of the booster indicated that all test objectives were successfully met during the hotfire.

QM-2 now planned for summer 2016 will be a test of the motor chilled to 40 degrees $F$, the low end of its operating range. The fifth and final segment for the test was delivered to the Utah test site in early March 2016. (Figure 3, right). Significantly, work has already begun on preparing the motor hardware for EM-1.

\section{RS-25 CORE STAGE ENGINE}

Core Stage propulsion for SLS will be provided by four RS-25 LH2/LOX RS-25 engines manufactured by Aerojet Rocketdyne. Formerly known as the Space Shuttle Main Engine, this propulsion system remains one of the most powerful, proven, and efficient engines in the world. SLS currently has 16 remaining flown engines from the Shuttle Program to power the first four SLS missions. The available flown engine inventory will be operated at 109 percent thrust vs. 104.5 percent for the shuttle, increasing engine output from 491,000 pounds to 512,000 pounds of thrust.

The heritage engines are being updated with a new engine control unit (ECU) and additional nozzle insulation for the higher base heating environment resulting from four engines versus the shuttle's three, as well as their location in plane with the booster exhaust nozzles.

In 2015, the SLS team completed a seven-test hotfire test series with development engine \#0525 totaling more than 3,700 seconds with developmental engine \#0528. The series, conducted at NASA's Stennis Space Center (SSC), confirmed that the shuttle-heritage engines can operate under SLS performance requirements and launch environments. The engines will encounter colder LOX temperatures than the shuttle due to their location and a new engine conditioning process, as well as higher inlet pressures due to the taller Core Stage and greater vehicle acceleration.

Testing also supported development of the new ECU and nozzle insulation, as well serving as an important checkout of the refurbished A-1 test stand, including a new thrust measurement system.

Engine hotfire testing is continuing in calendar year 2016, beginning with EM-2 flight engine 2059 in March. (Figure 4) (EM-1 engines will be tested as part of the EM-1 stage green run test at Stennis.) The test of 2059 provided a known flown engine performance baseline for calibrating the refurbished test stand, as well as green running the engine's high pressure fuel turbopump, and continued controller development. Still upcoming, \#0528 will be hotfire tested three times by the end of the year. Objectives include green running new flight engine controllers, flight software, and continuing SLS adaptation testing.
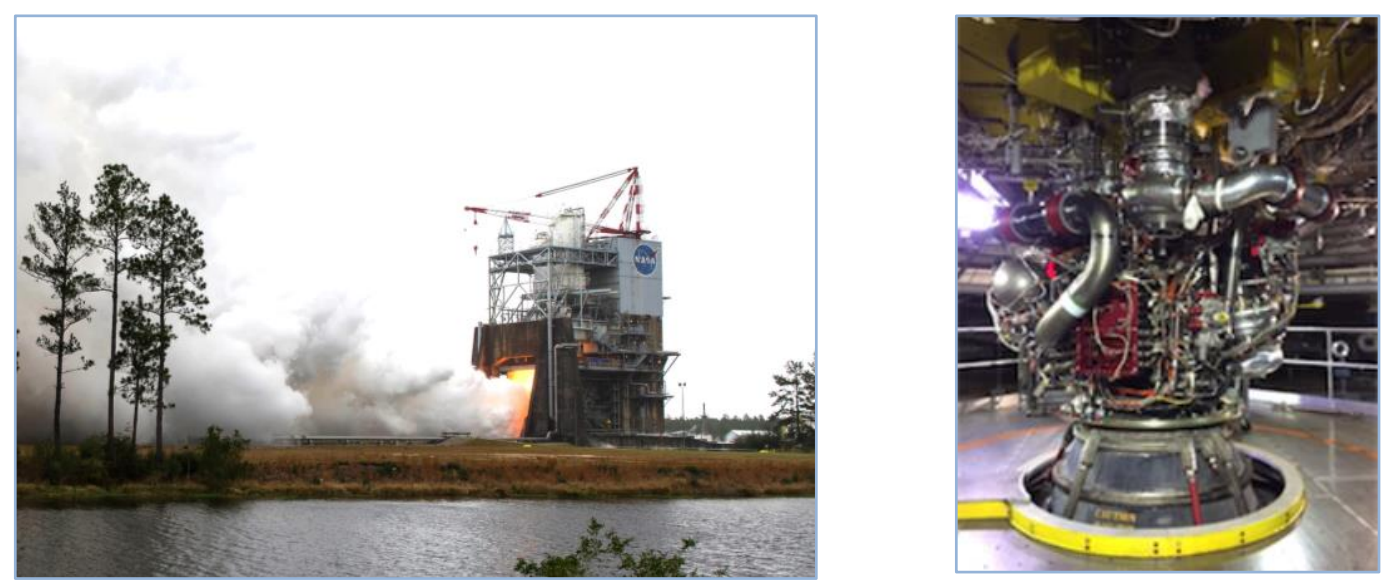

Figure 4. Left, 500-second hotfire test of RS-25 for EM-2, March 2016. Right, Engine 2059 in A1 test stand, Stennis Space Center. 
NASA began working with Aerojet Rocketdyne to restart RS-25 production. This work involves re-establishing our vendor base for the RS-25 and making changes to the design to make it more affordable and expendable to support missions after the current inventory is used. New engines will be operated at 111 percent thrust, a level tested but not flight-certified during the Shuttle Program.

\section{CORE STAGE}

The Core Stage was designed to accommodate the shuttle heritage engine and booster designs and support vehicle evolution to include new upper stages, boosters, and payload shrouds. The stage measures $64.6 \mathrm{~m}$ ( $212 \mathrm{feet}$ ) tall and $8.3 \mathrm{~m}$ (27.6 feet) in diameter. Major components are the liquid hydrogen (LH2) tank (LH2), liquid oxygen (LOX) tank, intertank, forward skirt, and engine section, which houses 4 RS-25 engines. Booster attachment points are located on the intertank and engine section. The Core Stage contains the flight avionics, including flight computers, instrumentation, batteries, power handling, sensors, and other electronics.

Designed by The Boeing Co., the Core Stage is currently being manufactured at NASA's Michoud Assembly Facility (MAF). Flight stages will be green run at the Stennis field center's B-2 test facility before shipment to Kennedy Space Center for vehicle assembly.

Six primary state-of-the-art manufacturing tools are used to assemble the core stage. The largest is the 170-foottall Vertical Assembly Center, the final step in joining the domes rings and barrels that make a completed section. The exception is the intertank, which is a bolted structure.

The manufacturing schedule was interrupted in 2015 when the VAC, the largest spacecraft welding tool in the world, was found to be out of alignment roughly 5 centimeters $(\mathrm{cm})(1.9$ inches) over the length of the tower components. Correction required the tower to be disassembled, corrected and reassembled. Welding of major components began in late 2015 and progressed rapidly in early 2016. (Figure 5)

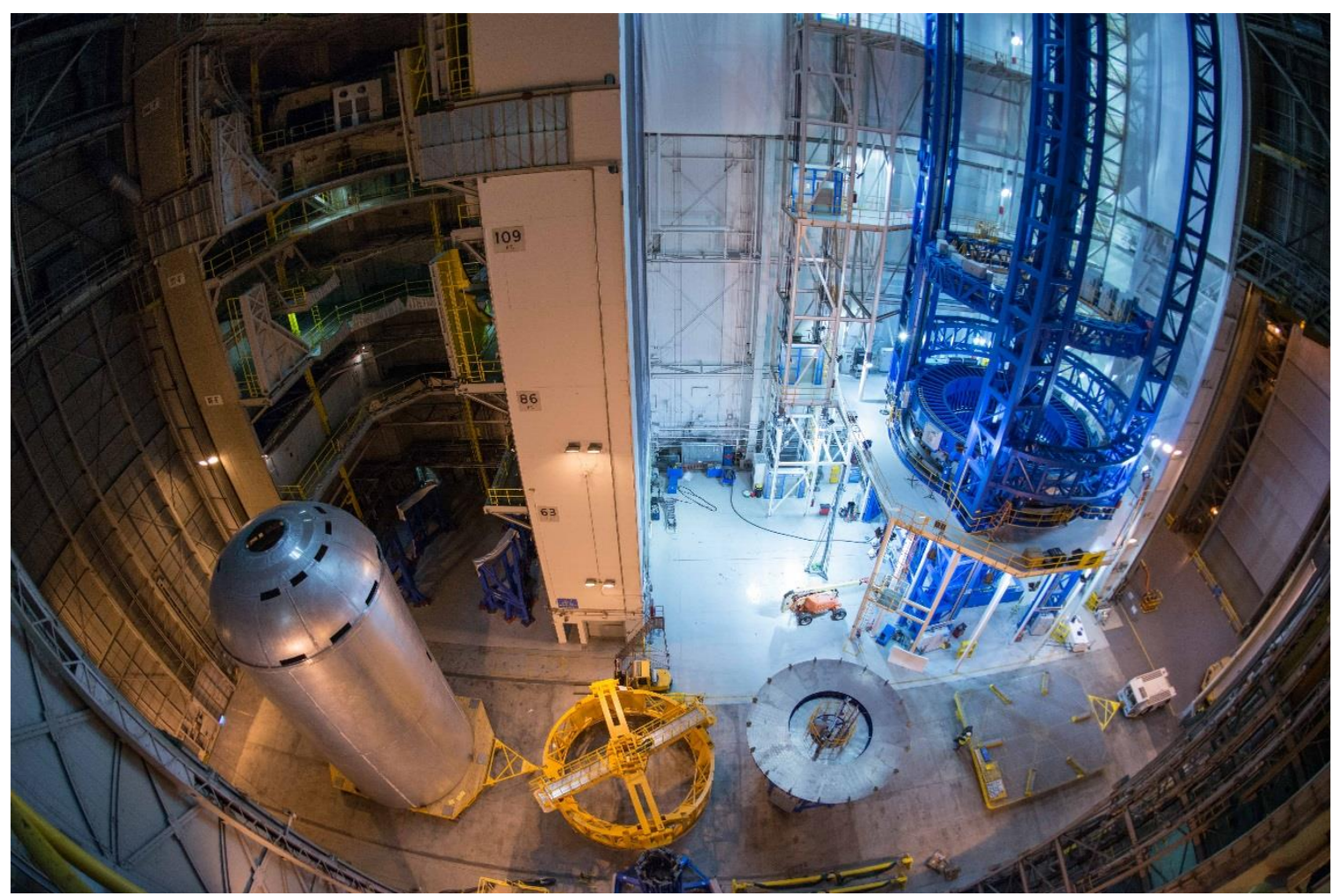

Figure 5. SLS core stage liquid hydrogen tank weld confidence article, left, completed welding on Vertical Assembly Center, February 2016, at Michoud Assembly Facility. 
Prior to welding flight hardware, manufacturing started with weld confidence articles for the LH2, LOX and engine sections. These test articles verified that welding temperatures, speeds, and other processes work as planned and tooling-to-hardware interfaces are correct. It also provided the weld team with experience bringing all aspects of hardware, tooling, and software together.

Confidence articles are followed by qualification articles that closely replicate flight hardware and processing. LH2, LOX, intertank, and engine section structural test articles (STAs) will be shipped to Marshall Space Flight Center by barge for structural testing.

Weld confidence articles have been completed and manufacturing is currently on schedule to complete all primary structural welding on structural test articles and flight hardware for Core Stage 1 (CS-1) by mid-summer 2016. All major components are completed and in line for welding in the Vertical Assembly Center (VAC) based on need dates for outfitting and testing.

\section{OTHER WORK}

In addition to stage manufacturing, flight avionics development and testing made progress in 2015. The System Integration Test Facility- Development (SITF-D) was disassembled in late 2015 and System Integration Test Facility - Qualification (SITF-Q) construction began, while avionics deliveries continued in support of testing later in 2016 .

Work continued on the LH2, LOX, intertank, and engine section structural test facilities at the Marshall field center with work expected to be completed in 2016. (Figure 6) United Launch Alliance completed the ICPS test article in late 2015. Production of the ICPS flight unit for EM-1 is under way and scheduled for completion in late 2016.
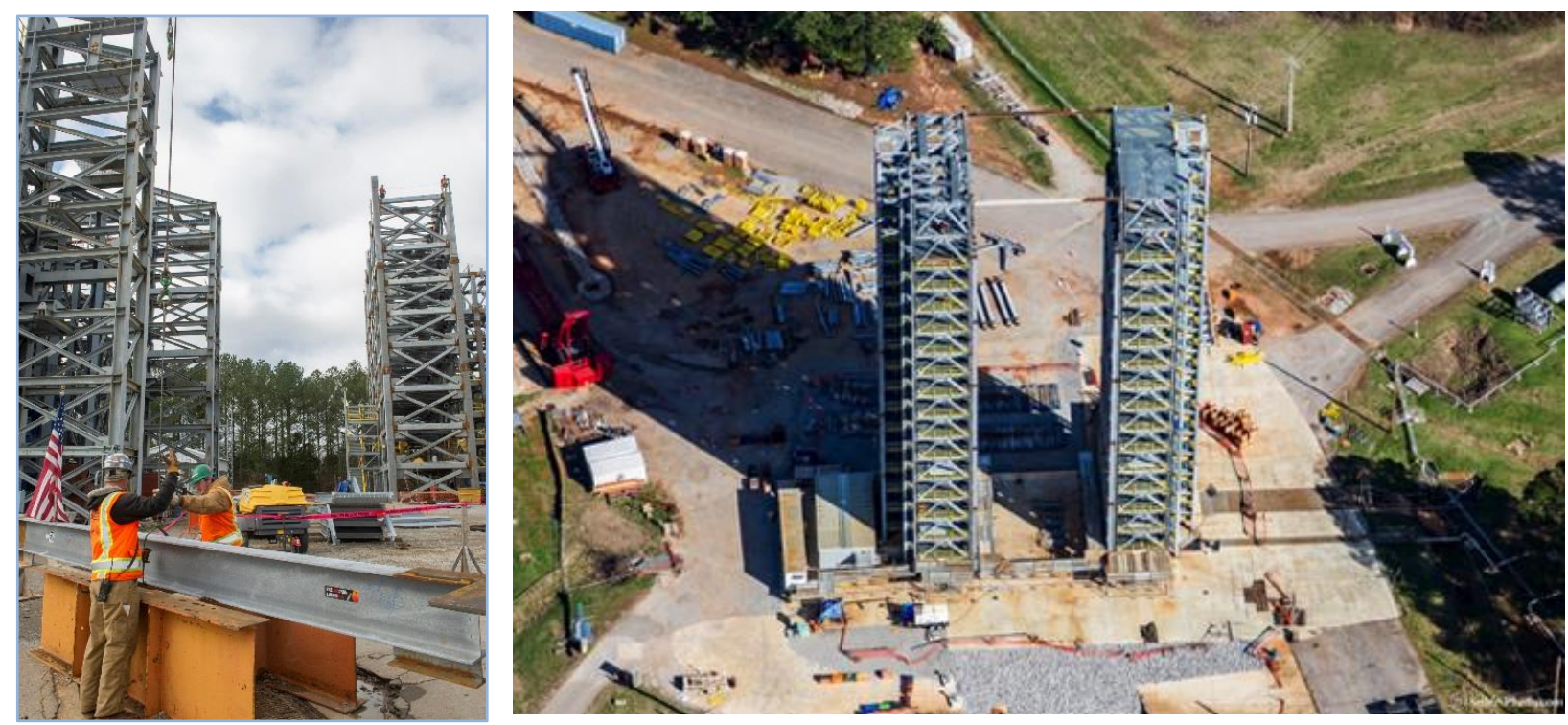

Figure 6. Left, LOX Test Stand 4697 under construction. Right. Outfitting under way on LH2 Test Stand 4693, early 2016, MSFC. 
Welding was completed on the test article for the launch vehicle stage adapter (LVSA) that will connect he core stage to the Interim cryogenic Propulsion Stage (ICPS). The test article will be stacked with the ICPS test article and other test articles of the upper part of SLS for structural tests at Marshall in late 2016. (Figure 7)

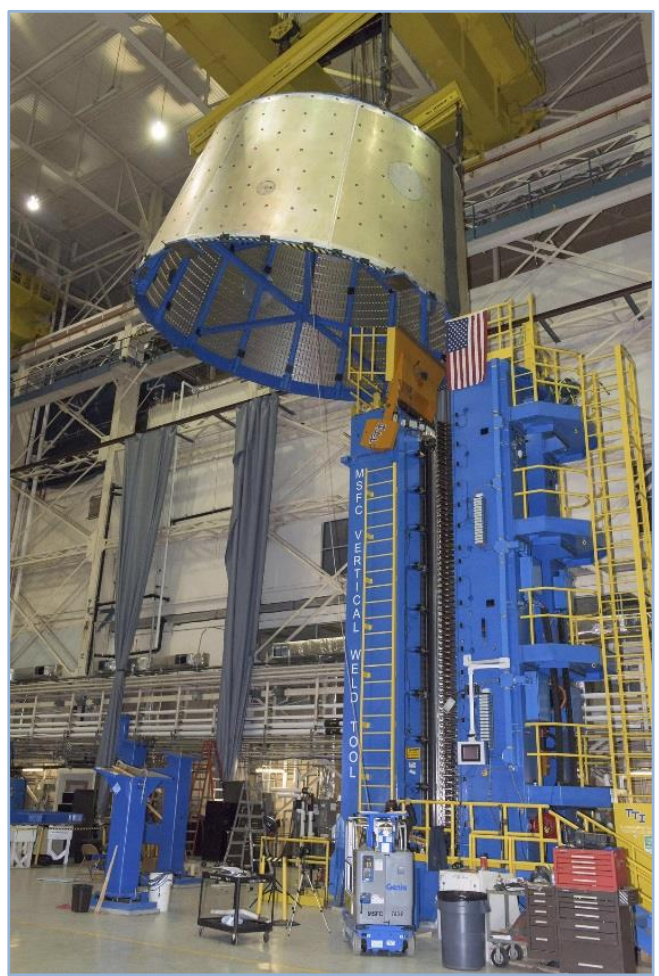

Figure 7. Aft cone of LVSA completes final vertical weld at MSFC, January 2016.

Refurbishment of the B-2 stand at Stennis continued with piping and electrical restoration, construction of new upper super structure to support CS-1.

NASA awarded a contract for construction of a core stage pathfinder article for testing equipment and facilities that support stage transportation, testing and assembly.

The Pegasus Barge was delivered to Stennis Space Center in August 2015 after modifications that expanded the total length of the barge from 260 feet to 310 feet. (Figure 8) The expansion will allow the barge to transfer Core stage propellant tanks and other components to Marshall and Stennis for testing and eventually to Kennedy Space Center for launch.

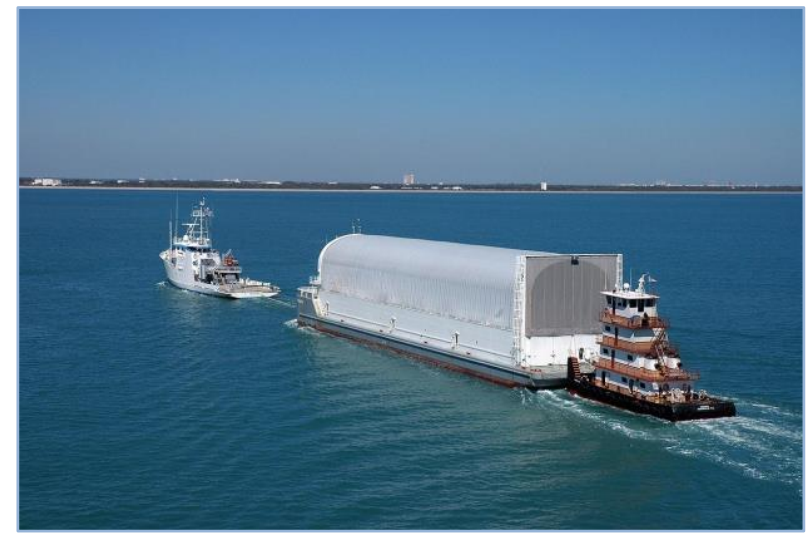

Figure 8. Pegasus Barge delivered to Stennis Space Center in July 2015. 


\section{CONCLUSION}

The world's most powerful rocket for exploration is being built today for an initial flight in 2018. This paper is only a snapshot of the significant progress to date. Every major component of the Space Launch System has hardware and software in manufacturing and testing. SLS is the key to enabling a new era of U.S. leadership in space exploration, spur economic growth, and expanding human knowledge and accomplishment. 